\title{
INVESTIGAÇÃO NARRATIVA NA FORMAÇÃO DE PROFESSORES DE QUÍMICA
}

\author{
NARRATIVE INVESTIGATION IN THE EDUCATION PROCESS OF \\ CHEMISTRY TEACHERS
}

\section{INVESTIGACIÓN NARRATIVA EN LA FORMACIÓN DE PROFESORES DE QUÍMICA}

\author{
Aline Machado Dorneles* \\ Professora assistente da Universidade Federal do Rio Grande \\ Maria do Carmo Galiazzi** \\ Professora Associada da Escola de Química e Alimentos e do Programa de Pós- \\ Graduação em Educação em Ciências da Universidade Federal do Rio Grande
}

Resumo: No presente artigo apresenta-se um processo de investigação narrativa na formação de professores de Química, a partir de narrativas das experiências de formação e de experiências pedagógicas vividas no meu fazer profissional de professora universitária em início de carreira. Para isso, faz-se uma articulação das histórias de uma das pesquisadoras no campo da pesquisa narrativa, com compreensões teóricas e, assim, constroem-se argumentos a respeito da importância desse modo de fazer pesquisa, em que o professor, pela escrita narrativa, torna-se autor da sua prática educativa. Nesse sentido, entende-se que as experiências, quando documentadas de forma narrativa, potencializam os processos colaborativos de conversa, de leitura, escrita e reescrita, na formação de professores de Química.

Palavras-chave: Investigação narrativa. Formação de Professores. Experiência.

\footnotetext{
* Mestre em Educação em Ciências, doutoranda do Programa de Pós-Graduação em Educação em Ciências da Universidade Federal do Rio Grande.

** Doutora em Educação pela Pontifícia Universidade Católica do Rio Grande do Sul; Bacharel em Química pela Universidade Federal do Rio Grande do Sul
} 
Abstract: In this paper, I have introduced a narrative investigation process in Chemistry teachers' education based on the narratives of my experiences in teacher education and of pedagogical experiences I have gone through as a professor at the beginning of the career. In order to carry out this study, I have intertwined my stories in the field of narrative research and theoretical proposals to construct arguments regarding the importance of this kind of research in which a professor becomes the author of his/her own educational practice through narrative writing. Therefore, I believe that when experiences are written down as narratives, they potentialize collaborative processes of conversation, reading, writing and re-writing in the education processes of Chemistry teachers.

Keywords: Narrative investigation. Teacher education. Experience.

Resumen: En este artículo presento un proceso de investigación narrativa en la formación de profesores de Química a partir de las narraciones de experiencias de formación y de experiencias pedagógicas vividas en mi quehacer profesional de profesora universitaria en el inicio de la carrera. Para tal fin, realizo una articulación de mis historias en el campo de la investigación narrativa con comprensiones teóricas, y así, construyo argumentos al respecto de la importancia de este modo de hacer investigación, en el que el profesor por medio de la escritura narrativa se convierte en autor de su práctica educativa. En ese sentido, entiendo que las experiencias al ser documentadas de esta forma, potencializan los procesos colaborativos de diálogo, de lectura, de escritura y reescritura en la formación de profesores de Química.

Palabras clave: Investigación narrativa, Formación de profesores, Experiencia.

\section{INTRODUÇÃO}

Apresento a seguir, um estudo teórico articulado com minhas compreensões a respeito da investigação narrativa na Educação Química. As reflexões teóricas construídas foram entrelaçadas pelas histórias em que me constituí professora e pesquisadora narrativa. Decidi pela pesquisa narrativa, por entender que um estudo não se faz só, então mesmo que esse texto seja escrito em primeira pessoa, nele há a presença do outro, com quem aprendo e partilho experiências de ser professora que investiga sua prática educativa. Por isso, o envolvimento com pesquisa narrativa me faz acreditar e argumentar que esse é o meu modo de fazer pesquisa na formação de professores.

As compreensões teóricas e as histórias por mim narradas são oriundas da minha pesquisa de tese de doutorado que propõe Rodas de Investigação Narrati- 
va da experimentação na formação de professores em um curso de Licenciatura em Química da Universidade Federal do Rio Grande (FURG). Proponho um processo de investigação - ação - formação, fundamentada nos aportes teóricos e metodológicos da pesquisa narrativa (CLANDININ; CONNELLY, 2011).

Assim, primeiramente apresento a investigação narrativa como possibilidade de construção e reconstrução do conhecimento químico e o conhecimento pedagógico na formação de professores de Química. A escrita narrativa é apresentada como dispositivo, para documentar as experiências de sala de aula, pois entendo que as experiências, quando documentadas de forma narrativa, potencializam os processos colaborativos de conversa, leitura, escrita e reescrita na formação de professores de Química.

Num segundo momento, alguns elementos estruturantes da escrita narrativa são apresentados como possibilidade de trilhar um caminho metodológico na ação de narrar histórias a partir de Bruner (2001), que percebe a narrativa como um modo de pensamento e de produção de significados; também por meio da ação simbólica de Burke (1969), representada por seu quinteto dramatístico, o qual permitiu interpretar e analisar as histórias escritas na formação de professores.

Finalizo com as histórias que me constituem pesquisadora narrativa num espaço tridimensional da pesquisa narrativa, espaço em que as investigações são realizadas no campo da formação de professores de Química. Narro o espaço tridimensional da pesquisa narrativa como forma a retratar as dimensões do tempo, do espaço, do pessoal e social na pesquisa.

\section{INVESTIGAÇÃO NARRATIVA: PONTOS BORDADOS NA FORMAÇÃO}

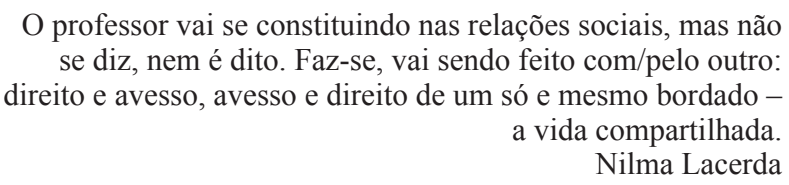

Na metáfora do bordado trazida nas palavras de Nilma Lacerda, no livro $M a$ nual de Tapeçaria, percebo o aprender com outro e a partilha de saberes que acontece em rodas de conversa e de formação (SOUZA, 2011). Também faço desse texto um trabalho artesanal, um convite à bordadura da formação de professores, em que diferentes bordados são construídos, bordados realizados com a presença de artesãos experientes que nos ensinam a definir pontos, linhas e cores para dar continuidade ao trabalho. 
O encontro com a metáfora do bordado faz com que recorde do tempo que bordava entre linhas e pontos, ainda criança, ensinada pelas mulheres da família, diferentes motivos que, para mim, tinham um significado para serem realizados com tanto cuidado e dedicação. Da mesma forma, encontro-me na formação de professores, na bordadura de histórias e percebo que é possível bordar diferentes contextos que nos constituem enquanto professores em formação.

Compreendo que a forma narrativa nos constitui enquanto seres humanos, vivemos contando histórias que nos constituem enquanto professores e pesquisadores. Somos constituídos de fragmentos narrativos, decretados em momentos históricos de tempo e espaço,-refletidos e entendidos em termos de unidades narrativas e descontinuidades (CLANDININ; CONNELLY, 2011).

Nesse sentido, busco compreender meu papel na investigação narrativa, que não é de um pesquisador que "coleta de informações". Na pesquisa narrativa, o pesquisador é um dos participantes da investigação e aprende com suas próprias histórias e com as histórias de seus participantes. Segundo Clandinin e Connelly (2011, p. 96), "Não são apenas as histórias dos participantes que são recontadas por um pesquisador narrativo. São também as histórias dos pesquisadores que são abertas para pesquisar e recontar."

A pesquisa narrativa é outra forma de se fazer pesquisa acadêmica. Os mesmos autores afirmam que existem tensões entre a pesquisa narrativa e a forma como se costuma fazer pesquisa. Uma das tensões centrais é pensar o lugar da teoria na pesquisa narrativa. É comum começar a pesquisa pela teoria, porém os pesquisadores narrativos tendem a começar com a experiência assim como é expressa, em histórias vividas e contadas. Por isso, a seguir relaciono uma história em que narro os entremeios da pesquisa narrativa:

Nas leituras a respeito da pesquisa narrativa os autores Clandinin e Connelly (2011) me possibilitaram um percurso retrospectivo, sobre as histórias que me constituíram e me constitui professora de Química. Tudo isso ocorre em um lugar na FURG, ambiente em que fui acadêmica e hoje sou professora e pesquisadora, no qual construo minha paisagem do conhecimento profissional.

Poderia contar as histórias da minha formação acadêmica, mas decidi escrever as histórias de experiências profissionais, por entender que meus saberes e vivências estão entrelaçados com a minha formação inicial, refletindo os conhecimentos que me constituem o ser professora e pesquisadora na área da Educação Química.

Nesse lugar construo histórias de experiências no viver, contar, reviver e recontar o processo de formação, histórias que marcam um trabalho coletivo. Sim, penso ser uma característica que nos leva apostar na pesquisa narrativa, o coletivo, as his- 
tórias que constituem os sujeitos participantes desse processo de formação.

Pensar a pesquisa narrativa na Química começou durante a pesquisa de mestrado, em que foi o objetivo, aprender com as histórias de sala de aula de professores da educação básica. Já tinha a ideia de aprender com o outro, pois a cada história lida e conversada outras aprendizagens eram construídas. Construí história na pesquisa narrativa, e na pesquisa de doutorado narro esse percurso que me constitui pesquisadora narrativa junto aos demais colaboradores da pesquisa (Diário da pesquisadora - maio/2014).

Nessa escrita busco um contar do passado (movimento retrospectivo), que é relacionado ao presente, um exercício inicial do processo de investigação narrativa. Nesse contar destaco a importância do coletivo, configurando-se num espaço tridimensional da pesquisa:

[...] como pesquisadores narrativos não estamos sozinhos nesse espaço. Esse espaço envolve a nós e àqueles com quem trabalhamos. A pesquisa narrativa é uma pesquisa relacional quando trabalhamos no campo, movendo-nos do campo para o texto do campo, e do texto do campo para o texto da pesquisa. (CLANDININ; CONNELLY, 2011, p. 96).

O engajamento dos docentes num processo de formação pode ocorrer por meio da pesquisa narrativa, pois permite que diferentes atores se envolvam no processo: professores do ensino básico, licenciandos e professores da universidade, constituindo, assim, uma rede de diferentes olhares e diferentes histórias, em que as ideias e os saberes sobre ser professor são partilhados no coletivo. A escrita narrativa é uma das ferramentas culturais adotadas para compreender o processo de formação do professor. Além disso, é um enfoque particular de pesquisa que procura envolver o professor, sendo ele, na maioria das vezes, o ator do enredo a ser pesquisado (SUÁREZ, 2008).

No ato de investigar o espaço escolar e a atuação docente por meio da pesquisa narrativa, os professores, no referido processo de formação, podem narrar experiências, fatos, ações que significam sua sala de aula como problematizadora e formativa. Em outros momentos, podem narrar situações problemáticas, para as quais não encontram respostas; fazem perguntas, partilham com o outro, no sentido de ouvir o que ele vivencia na sua sala de aula. A investigação narrativa tem dessas "coisas": promove a mediação, o acolhimento e o espaço para expressar as experiências, os sentimentos e os dilemas da vida profissional e do ser professor.

A pesquisa narrativa possibilita o exercício de contar a experiência da docência e os fatos relacionados como significativos na sala de aula, configurando as his- 
tórias enquanto produtoras de conhecimento. A experiência, quando narrada, permite voltar aos saberes passados para interpretá-los e recordá-los, mas é necessário o olhar atento no presente, o qual possibilita que as lembranças significativas de um passado distante ou breve, sejam narradas e partilhadas com o outro (BARBOSA, 2003). "Na experiência da narrativa, vive-se a experiência do outro como se fosse genuinamente pessoal. E, nessa polifonia de histórias, é possível continuar narrando a história que já foi do outro e configurar, então, outros sentidos.” (LIMA, 2005, p. 48). Assim, são nas diferentes histórias narradas que os docentes se compreendem em um processo de formação e aprendem com o outro, nas conversas a respeito das suas práticas educativas. Reforço tal posicionamento apoiada em Suárez (2010, p. 183):

Quando os docentes se convertem em narradores de suas próprias experiências escolares, deixam de ser o que eram, se transformam, são outros. Assumem uma posição reflexiva que desafia as próprias compreensões, reconfiguram as próprias trajetórias profissionais e ressignificam as próprias ações e interpretações sobre a escola.

A investigação narrativa na formação possibilita o exercício da autoria nas suas histórias de sala de aula, como também a construção e reconstrução de saberes, o acolhimento e a afetividade, quando se narra as experiências vividas na formação. Nesse sentido, Larrosa (2011, p. 5-6, grifo do autor) diz que:

\begin{abstract}
A experiência supõe em primeiro lugar um acontecimento. Não há experiência, portanto, sem a aparição de alguém, ou de algo, ou de um isso, de um acontecimento, que é exterior a mim, estrangeiro a mim [...]. Supõe também, em segundo lugar, que algo me passa. Não que passe ante mim, ou frente a mim, mas a mim, que dizer, em mim. A experiência supõe, como já afirmei, um acontecimento exterior a mim. Mas o lugar da experiência sou eu.
\end{abstract}

A experiência, quando narrada nas histórias dos professores, expressa os lugares que ocupam, os papéis que desempenham, as múltiplas relações sociais que estabelecem historicamente; assim, narram suas próprias experiências e constituem-se autores do mundo escolar e nele tecem sua lida diária (LIMA, 2005; SUÁREZ, 2008).

A experiência, quando escrita, favorece a reflexão a respeito do fato narrado; logo, o desafio que se estabelece é o de escrever sobre a experiência da docência e, nesse sentido, Marques (1997) argumenta que se escreve para pensar e não ao contrário: pensar para escrever. Assim, entendo que as histórias, ao serem narradas, são dispositivos para se pensar acerca da formação do professor e, nessa direção, possibilita ao autor da história e ao outro que a lê pensar sobre sua ação docente e sua formação, 
viabilizando que outras histórias possam ser narradas. A escrita narrativa, desse modo, produz significados, pensamentos e sentidos da formação.

\section{A AÇÃO DE ESCREVER NARRATIVAMENTE}

A narrativa permeia diferentes espaços da escola: a sala de aula, as reuniões pedagógicas, as conversas dos professores e suas práticas educativas. Nesse sentido, o mundo escolar é constituído por fragmentos narrativos, encenados em diferentes momentos, espaços e tempos, que podem ser entendidos em termos de unidades narrativas (CLANDININ; CONNELLY, 2000; SUÁREZ, 2008, 2010, 2011). Contudo, nem sempre essa narração é compreendida como uma ação formativa para os docentes. Então, como narrar histórias e aprender com os contextos narrados?

$\mathrm{O}$ ato de narrar e escrever histórias faz parte da ação humana, começando na infância, quando histórias são imaginadas, contadas e ouvidas com atenção. Visto sob tal perspectiva, o formato narrativo é, provavelmente, a forma mais natural e recorrente de expressar a experiência e o conhecimento (BRUNER, 2001). Como as histórias constituem os sujeitos, percebo que o exercício de escrever as lembranças por meio da narrativa torna-se agradável e pode fomentar o desejo pela escrita.

Entendo a escrita narrativa como forma de perceber os aspectos cognitivos da experiência, no caso analisado, da experiência docente. Sustento meu posicionamento a partir dos estudos de Bruner (2001), que buscam compreender a narrativa por meio do seu significado, que seria aquilo que os textos querem narrar. $\mathrm{O}$ autor citado entende a narrativa "como um modo de pensamento, como uma estrutura para a organização de nosso conhecimento e como veículo no processo de educação.” (BRUNER, 2001, p. 117).

Seguindo a ideia defendida por Bruner (2001), as narrativas têm como característica o fato de envolver uma sequência de eventos em que o narrador da história escolhe o que deve ser narrado, quais detalhes serão revelados ou não, possibilitando que a história seja envolvente para quem lê e ainda conversa com a trama narrada. Assim, a narrativa é justificada pelo argumento de que a sequência de eventos narrados é uma violação da canonicidade: narra-se algo inesperado ou algo que o leitor tem motivo para duvidar. A esse respeito, Bruner (2001, p. 119) afirma que:

O "motivo" da narrativa é resolver o inesperado, eliminar a dúvida do leitor ou, de alguma forma, corrigir ou explicar o "desequilíbrio" que, antes de mais nada, fez com que a história fosse narrada. Uma história, portanto, tem dois lados: uma sequência de eventos e uma avaliação implícita dos eventos narrados. 
Mas, como explicar por que os docentes narradores elegem esta e não aquela sequência de eventos? Que situações inesperadas ou não canônicas querem narrar? Que motivos querem envolver o leitor nas histórias que contam? Tais questionamentos reforçam a necessidade de interpretação para se entender o que narram as histórias (BRUNER, 2001).

Nesse caminho, busco compreender o ato de narrar histórias de sala de aula na formação de professores por meio dos estudos acerca da narrativa, na perspectiva de Bruner, relacionando-o à definição de ação simbólica de Burke (1969), sendo a mesma uma compreensão da composição dos textos, nesse caso, as histórias. Uma compreensão que destaca não o que os textos a princípio são, mas o que acontece por meio desses textos para torná-los diferentes uns dos outros (PASSOS, 1998; WERTSCH et al., 1998).

O conflito, o propósito, a reflexão e a escolha, presentes nas histórias, possibilitam que os professores, pela narrativa, façam o exercício de simbolizar sua sala de aula, pois, segundo Bruner (2001), o que contamos nas histórias nunca é por acaso. A história é motivada por desejos, teorias, valores e outros estados intencionais. Nesse movimento, percebe-se a ação do drama de Burke (1969), que permite, por meio do "quinteto dramatístico", a investigação dos motivos envolvidos no desenvolvimento de um largo espectro de ações humanas (WERTSCH et al., 1998).

O dramatismo engloba observações deste tipo: para haver um ato, deve haver um agente. Paralelamente, deve haver uma cena na qual o agente age. Para agir em uma cena, o agente deve empregar alguns meios, ou instrumentos, e pode ser chamado de um ato no sentido amplo do termo somente se envolver um propósito. (BURKE, 1969, p. 445 apud WERTSCH et al., 1998, p. 22).

A ação de narrar histórias envolve as características presentes no quinteto dramatístico de Burke. Assim, quais os modos de ação envolvidos nas construções das histórias de sala de aula? A resposta se dá que a ação narrada envolve as escolhas que constituem a identidade do sujeito e se orientam, na maioria dos casos, pela presença de outro sujeito (PASSOS, 1998). Na escrita de uma história, as características do quinteto facilitam a compreensão do que está sendo narrado e a relação com o outro configura a ação narrada como significativa e relevante.

É importante que a cena narrada seja envolvente, pois será o principal elemento da história, da mesma forma que o ato e os agentes que pertencem à cena. Dessa maneira, Burke (1969) destaca que: 
Uma "cena" no sentido de conjunto, ou pano de fundo, e "ato" no sentido da ação, pode-se dizer que a "a cena contém o ato". E usar "agentes" no sentido de "atores", Pode-se dizer que "a cena contém os agentes". [...] Ou se você preferir o cenário (ex: a cena) contém ação ambiguamente (com relação às normas da ação) - e no decorrer da peça essa ambiguidade é convertida numa articulação correspondente. A proporção seria: a cena está para o ato assim como o implícito está para o explícito. (BURKE, 1969 apud WERTSCH et al., 1998, p. 25).

As categorias descritas por Burke não são estáticas e formais a ponto de poderem ser usadas para descrever a ação do sujeito como única na história que escreve. Ao contrário, compreende-se que a ação é, muitas vezes, se não sempre, aberta a interpretações mais profundas porque existem ambiguidades surgidas ao se considerar os elementos que interagem dialeticamente (WERTSCH et al., 1998).

Acredito ser relevante relacionar a escrita narrativa com o quinteto dramatístico de Burke, por permitir interpretar a ação narrada. Compreendo que o caminho metodológico trilhado pelos estudos do quinteto dramatístico de Burke permitiu a análise das narrativas de forma a explicitar essas interpretações num texto narrativo, global e único.

Assim, componho, a seguir, um texto narrativo de pesquisa, num espaço tridimensional de pesquisa, em que narro lembranças do passado e encontro razões pessoais que me levam a apostar nesse estudo, como também narro o significado social da minha pesquisa na formação de professores de Química.

\section{O VIVER E REVIVER HISTÓRIAS NA FORMAÇÃO DE PROFESSORES DE QUÍMICA}

Na pesquisa narrativa vivemos histórias e no contar dessas histórias nos reafirmamos, nos modificamos e criamos novas histórias (CLANDININ; CONNELLY, 2011). Mas, o que faz o pesquisador narrativo? O pesquisador narrativo tem interesse em viver e reviver a experiência, para isso, os termos da investigação narrativa possibilitam pensar o ato de fazer pesquisa narrativa, fundamentada na visão de Dewey sobre a experiência na concepção da narrativa, que são pessoal e social (interação); passado, presente e futuro (continuidade) e o lugar (situação). Conforme os autores:

Este conjunto de termos cria um espaço tridimensional para investigação narrativa, com a temporalidade ao longo da primeira dimensão, o pessoal e social ao longo da segunda dimensão e o lugar ao longo da terceira. Utilizando esse conjunto de termos, qualquer investigação em particular é definida por este espaço 
tridimensional: os estudos têm dimensões e abordam assuntos temporais, focam no pessoal e social em um balanço adequado para investigação e ocorrem em lugares específicos ou sequências de lugares. (CLANDININ; CONNELLY, 2011, p. 85).

A metáfora do espaço tridimensional de investigação narrativa é compreendida também pelos autores em quatro dimensões: introspectivo (condições internas, como sentimentos, esperanças, reações estéticas); extrospectivo (condições existenciais - meio ambiente); retrospectivo e prospectivo que se refere à temporalidade (passado, presente e futuro), localizadas no lugar. Assim, “experienciar uma experiência - isto é, pesquisar sobre uma experiência - é experiênciá-la simultaneamente nessas quatro dimensões, fazendo perguntas que apontem para cada um desses caminhos" (CLANDININ; CONNELLY, p. 86).

$\mathrm{Na}$ dimensão introspectiva da investigação narrativa é importante a produção do diário de campo, com as interpretações do pesquisador atento às questões sociais, olhando interna e externamente, não apenas para o evento a ser investigado, mas para as histórias que constituem seu passado e os propósitos do presente e futuro (continuidade do tema pesquisado).

Mello (2005) afirma que na pesquisa narrativa a perspectiva de estudo amplia-se, e é possível analisar, por exemplo, o currículo como um evento na sala de aula, em que emergem as histórias vividas no lugar, mas também aquelas histórias não vividas, parte da experiência da pesquisadora e dos participantes trazida para sala de aula de alguma forma. Nessa perspectiva, a autora percebe uma postura mais crítica na investigação narrativa, que nos faz "considerar não somente o que ocorre e torna visível no evento, mas também a maneira como se percebe a experiência vivida." (MELLO, 2005, p. 102).

Compreender o espaço tridimensional da pesquisa narrativa torna-se importante, pois- favorece a perspectiva crítica de analisar o evento, não somente como espaço para coleta de dados de campo, mas, ao contrário, como espaço que potencializa a reflexão e transformação dos sujeitos envolvidos na pesquisa, pesquisador e participantes. Conforme os autores:

Enquanto trabalhamos no espaço tridimensional da pesquisa narrativa, aprendemos a olhar para nós mesmos com sempre no entremeio - localizado em algum lugar ao longo das dimensões do tempo, do espaço, do pessoal e do social. Mas nos encontramos no entremeio também em outro sentido, isto é, encontramo-nos no meio de um conjunto de histórias - as nossas e as de outras pessoas. (CLANDININ; CONNELLY, 2011, p. 99). 
A imersão na pesquisa narrativa possibilitou compreender a experimentação investigativa como evento na formação de professores de Química, a partir das narrativas da experimentação (histórias vividas no evento) como também as narrativas da experiência de cada um ao vivenciar o evento.

A seguir narro uma história de como percebo o espaço tridimensional da pesquisa narrativa na minha constituição como professora e pesquisadora narrativa. Busco narrar uma história de trabalho construída ao longo da atuação profissional de professora de Química, nas dimensões do pessoal e social; passado, presente e futuro no lugar de investigação.

\section{UMA HISTÓRIA DE TRABALHO EM UM ESPAÇO TRIDIMENSIONAL NA FORMAÇÃO DE PROFESSORES DE QUÍMICA}

A narrativa é um caminho para entendimento da experiência. Nessa perspectiva, experiências são histórias que as pessoas vivem (CLANDININ; CONNELLY, 2011, p. 27). Então, a história que contarei a seguir será sobre experiências desse momento vivido enquanto professora e pesquisadora narrativa. Em outro momento, ao reler essa história, já não serei mais a mesma, e poderei ter outras interpretações e histórias para contar. O que justifica a minha escolha pela pesquisa narrativa é, principalmente, isso: a possibilidade de modificar-me nesse reviver, de experienciar uma experiência, ou melhor, pesquisar os caminhos que levam à experiência.

O espaço tridimensional da pesquisa narrativa o qual me constituo como professora e pesquisadora é a Universidade Federal do Rio Grande (FURG). Encontro-me no início de uma caminhada, de um bordado que vem sendo entrelaçado com histórias e desafios do ser professora e formadora no Curso de Licenciatura em Química. Nesse curso, ingressei como aluna no ano 2005 e, durante quatro anos, construí muitas aprendizagens, amizades e, principalmente, o encantamento pela profissão de professora.

O envolvimento com a escrita começou na graduação, quando escrevíamos nos portfólios dos estágios supervisionados as lembranças de um professor inesquecível, da nossa escola de infância e tantas outras memórias que foram relevantes para constituição da identidade profissional.

No mestrado aprendi a bordar os pontos da formação por meio das histórias de sala de aula narradas pelas professoras da Educação Básica. Lembro que a cada leitura dessas histórias, era levada a entrar no contexto narrado, imaginando-me professora de Química naquela sala de aula. Para buscar compreender o que as histórias 
contavam, foi preciso ir além do que as palavras escritas. Foi necessário interpretar o não narrado, tentar perceber o avesso do bordado, pois quem vê somente o lado direito, deixa de perceber a beleza e o cuidado com o acabamento do avesso de um bordado (DORNELES, 2013). Afinal, conhece-se uma boa bordadeira pelo avesso de sua obra, aprendizado de infância.

Outros bordados seguem sendo alinhavados, por pontos já trabalhados, em que minha experiência como bordadeira se faz presente. Os pontos podem ser até os mesmos, mas o motivo que se borda e as tonalidades das linhas é que fazem cada trabalho artesanal ser único. $\mathrm{O}$ trabalho continua, os bordados seguem sendo retratados pelos seus pontos e cores de linhas, a cada bordado, outras histórias são contadas, reconstruídas e recriadas. Então isso, talvez, seja o sentido de um bordado nunca ser o mesmo.

Assim, desafio-me a bordar histórias de um espaço tridimensional em que desenvolvo a investigação narrativa na formação de professores de Química. Fui provocada a narrar essa história de trabalho ao decidir fazer uma tese narrativa de doutorado, em que investiga a escrita narrativa como possibilidade de documentar as experiências de formação dos licenciandos de Química durante o desenvolvimento de atividades experimentais na componente curricular do Estágio Supervisionado II do Curso de Licenciatura em Química da FURG, história que darei continuidade a seguir.

Gostaria de dizer que esse espaço tridimensional de trabalho e investigação narrativa, em que conto e relembro nas histórias a seguir, não são só minhas, são histórias que escrevo com o outro, que aprendo com o outro, são histórias que contam a importância de um trabalho coletivo na formação de professores.

A investigação narrativa, aqui proposta, torna-se dispositivo para o desenvolvimento da experimentação no ensino de Química. A ideia é compreender a experimentação como um acontecimento na formação de professores de Química. É viver a experimentação como experiência para o professor. Nesse sentido, assumo o sentido filosófico do termo experiência, considerando que seja isso que nos acontece (LARROSA, 2002, 2011).

A experiência quando compreendida como isso que nos acontece, deixa de ser vista somente como a realização de uma técnica de "fazer experimentos" e a comprovação de teorias. Torna-se a experiência do sujeito, que é passo para incertezas, questionamentos e aprendizagens durante o percurso da formação. Larrosa (2011, p. 14) diz que "a experiência, ao contrário do experimento, não pode ser planejada de modo técnico. A experiência é um acontecimento, não pode ser causada, não pode ser antecipada como um efeito a partir de suas causas. $\mathrm{O}$ acontecimento escapa a ordem das causas e dos efeitos." 
Diante disso, como investigar a linguagem química na experimentação a partir da experiência? Quais as potencialidades da investigação narrativa na documentação das aprendizagens do ser professor e do conhecimento químico na experimentação? Essas perguntas e outras no decorrer da escrita me levam a construir o significado de investigar a experimentação pelo viés narrativo, pois as respostas são construídas nas histórias que conto, nas histórias vividas com os participantes da pesquisa e com as histórias do passado, sendo reconstruídas na pesquisa. "Torna-se um exercício introspectivo de contar sobre nós mesmos, o encontro de nós mesmo no passado por meio da pesquisa deixa claro que, como pesquisadores, nós, também, somos parte da atividade" (CLANDININ; CONNELLY, 2011, p. 97).

Nesse contar sobre nós mesmos remeto às lembranças de ingresso como acadêmica no curso de Química Licenciatura da FURG no ano de 2005. Estava decidida a exercer a carreira de professora, decisão pouco presente entre os mais de vinte colegas de turma. No curso, desde o início, embora goste de Química, nunca me chamaram atenção os laboratórios e suas vidrarias que, para muitos de meus colegas, foram a razão de seu ingresso no curso de Química. O meu encanto se deu mais forte com os estágios. Na medida em que fui entrando na escola, ficou fortalecida ainda mais minha vontade de exercer a profissão escolhida.

No curso, há cinco estágios supervisionados, desenvolvidos em proposta articulada com as escolas de ensino médio da rede estadual de ensino, a partir do segundo ano do curso até o final do quarto. Em cada estágio realizado, fui adquirindo experiências e me constituindo professora, por meio de um trabalho desenvolvido em parceria com o professor da rede pública, denominado tutor, e com os professores formadores da universidade. Os estágios tiveram temáticas claras: a imersão na escola no primeiro; a experimentação na escola no segundo; a análise da Política Nacional do Livro Didático no terceiro; o planejamento da sala de aula no quarto e, no último, a sala de aula e seus desafios para quem nela entra pela primeira vez como professora.

No estágio supervisionado II o foco era a experimentação no ensino de Química e o desenvolvimento, pelos licenciandos, de uma atividade experimental na escola. Foram propostas pelos professores leituras e discussões a respeito da experimentação no ensino de Química, durante os encontros da disciplina. Recordo da experimentação da combustão da vela e encontro minha reflexão no portfólio, em que destaco:

Tivemos uma aula experimental demonstrativa. Algumas perguntas foram feitas pela professora. A maioria da turma ficou em silêncio, o motivo deve ser insegurança, se iríamos falar certo ou não. Naquele momento, um experimento que parecia ser tão simples causou várias dúvidas. Mesmo a maioria falan- 
do pouco, a professora foi perguntando nossas opiniões e ao poucos foram surgindo respostas. A experimentação pode nos servir de exemplo de que é preciso questionar o aluno. Não apenas fazer o experimento para motivar o aluno ou para expor teorias sem dar a oportunidade de o aluno argumentar e questionar. (Portfólio reflexivo, 2007).

As lembranças da formação inicial nos estágios supervisionados do curso remetem à investigação realizada na pesquisa de tese, em que na componente curricular do Estágio Supervisionado II do Curso de Licenciatura em Química da FURG, constituiu o espaço de investigação que entendo ser contínuo, e não somente para "coleta de informações" para pesquisa. Compreendo a tese como processo contínuo de investigação, não como algo acabado depois da defesa e da escrita final.

Nos encontros do estágio supervisionado II partilho da experiência de ser professora com minha colega e professora orientadora da pesquisa de tese. E, o encaminhamento inicial da investigação narrativa é de escrever perguntas em relação ao fenômeno investigado, como exemplo, a combustão da vela, narrado logo a seguir.

Nesses dois semestres em que estamos juntas como professoras, penso que, primeiramente, buscamos desenvolver com os licenciandos uma formação horizontal, em que todos somos sujeitos aprendentes (BRANDÃO, 2005). Mas, há algo de muito especial, o afeto! O afeto se faz presente na Roda! Esse afeto talvez seja o elemento principal para o entendimento da experiência como aquilo que nos acontece na formação de professores (LARROSA, 2011). A história que narro a seguir remete essa nossa intenção de conceber a experimentação como acontecimento:

O experimento da vela é um experimento clássico do estágio supervisionado II, é realizado há mais de 10 anos pelos professores da Educação Química da FURG. Nesse primeiro semestre de 2015 decidimos que seria a atividade experimental inicial para processo de investigação na disciplina. Qual foi nosso primeiro encaminhamento? Fazer perguntas em relação ao fenômeno da combustão da vela. Decidimos constituir um coletivo que aprende com outro. A experimentação da combustão da vela foi proposta por nós professores da disciplina, pois buscamos constituir um espaço de formação horizontal de professores de Química, em que todos ali possam se sentir aprendentes ao investigar a experimentação proposta. A realização da experimentação se deu junto com as escritas das perguntas. Enquanto montávamos o material, a conversa se iniciava e uma folha rodava entre o grupo para o registro das perguntas. E foram várias, como: Podemos dizer que o oxigênio no vidro é o reagente limitante? O aumento da temperatura dentro do sistema fechado influencia no processo de combustão? Se trocasse a água por outro líquido? Ao invés de água na temperatura ambiente, colocasse água quente ou água gelada, o que aconteceria? $\mathrm{O}$ 
que aprendemos nessa aula? Na investigação do fenômeno da combustão da vela, observamos a mesma apagar ao ser coberta com o frasco de vidro, e posteriormente com água no recipiente observamos que a mesma sobe durante a combustão e o apagar da vela. Bom, como explicar tais fenômenos? Que conceitos químicos estão presentes?

Buscamos construção de argumentos coerentes para explicação dos fenômenos investigados, para isso elencamos os seguintes fatores: a temperatura, diminuição da energia do sistema, logo a vela se apaga e não há energia de ativação suficiente para manter a reação exotérmica (reação de combustão), dentre outros. Mas, como explicar tais fatores? Finalizamos a aula, e ficamos com vários questionamentos a respeito de como compreender os conceitos envolvidos no experimento. No próximo encontro da disciplina seguimos a investigação. Cheguei cedo à FURG, comecei organizar o material para nossa aula. A proposta foi isolar alguns fatores e investigá-los separadamente. Começamos com a temperatura. Aquecemos um béquer com a chama da vela e depois viramos o mesmo no frasco com água. O que teria que acontecer? Água subir. Mas, não subia. Foi então, que Jéssica buscou uma chapa de aquecimento no laboratório, repetimos o procedimento. Mas, a água não subia. Mas, o que fazer? Que explicação dar ao fenômeno observado? E, CO2 formado na reação de combustão da vela? Jéssica pergunta e ao mesmo tempo dá uma resposta: - pode ser ele o responsável para água subir. Nisso, outro integrante da Roda também concorda com a explicação do colega. O envolvimento foi tão intenso e a ansiedade era grande para ter as respostas ao fenômeno investigado. Então, Lisliane comenta. A professora Maria falou para aquecermos o frasco com água quente. Foi lá buscar a mesma. Realizamos o procedimento, e agora a água subiu! Bom, mas como explicar o fenômeno da temperatura no sistema? Pois somente aquecer o vidro não foi suficiente, tínhamos que aquecer o ar que fica dentro do copo, para isso quando se coloca água quente e se emborca o ar de dentro do recipiente fica quente e depois ao resfriar a água sobe. Entre conversas, escritas, e registros fotográficos do experimento se foram quatro encontros de discussão a respeito da experimentação da vela, isso me leva a pensar e argumentar que fazer experimentação na formação de professores de Química exige trabalho em grupo, escuta do outro, indagação, e o registro narrativo do que se aprendeu (Narrativa da experimentação do Estágio Supervisionado II - 04 de maio de 2014).

A escrita narrativa da experiência vivida na experimentação nos favorece repensar, reconstruir e reviver as aprendizagens relacionadas aos fenômenos químicos, como também as experiências de formação e pedagógicas do ser professor de Química. Nos dois últimos anos que trabalhamos juntas, conseguimos constituir um coletivo que aprende com outro, numa formação horizontal, em que todos ali se sentiam aprendentes ao investigar a experimentação proposta. 
Isso me leva a pensar o quanto é preciso sempre repensar e recriar nossa prática educativa. Compreender que os estágios supervisionados são espaços de formação profissional, por isso, a importância de fazer dos encontros da disciplina, encontros de formação e investigação da nossa prática educativa.

Assim, a investigação narrativa acontece no meu fazer profissional, no Curso de Química Licenciatura da FURG, em que as lembranças e histórias do presente e do passado são rememoradas e revividas. Nesse sentido, o espaço tridimensional da pesquisa acontece em um lugar - na universidade, no Curso de Química Licenciatura - lugar em que a pesquisa narrativa se realiza, com as histórias que construímos no pessoal e social, histórias nossas enquanto pesquisadores narrativos, histórias de professores e licenciandos do Curso de Química Licenciatura, histórias com as escolas da educação básica e seus professores parceiros no processo de formação.

$\mathrm{Na}$ história de trabalho que decidi narrar, existe um pano de fundo muito presente, que é a experimentação na formação de professores de Química. Procurei, primeiramente, narrar as experiências, sentimentos e momentos situados no presente, na dimensão temporal do fazer profissional. No contar, vou relembrando momentos do passado, num exercício retrospectivo à formação inicial, com fragmentos de histórias alinhavados na memória e refletidos na pesquisa, na minha constituição de pesquisadora narrativa na paisagem do conhecimento profissional.

\section{CONSIDERAÇÕES FINAIS}

Escrever a experiência com a investigação narrativa, as aprendizagens construídas com o outro, levam-me a argumentar a respeito da relevância da escrita narrativa na formação docente, como estratégia de documentar as experiências de sala de aula e de sentir-se autor das suas práticas educativas.

$\mathrm{Na}$ investigação narrativa temos a possibilidade de modificar-nos a partir das nossas histórias, de viver e reviver momentos da formação, de pesquisar os caminhos que levam à experiência, e transformar-se nesse processo de formação. Assim, reforço a importância do processo de escrita narrativa como dispositivo na formação de professores. O trabalho colaborativo favorece a indagação narrativa a partir da mediação dos outros, do coletivo de docentes narradores que escrevem, leem, comentam e conversam em torno das sucessivas versões do relato de experiência.

Para finalizar, retorno à metáfora do bordado com as palavras da autora Nilma Lacerda em que diz "o lado da lida, bordado com o mesmo ponto com que se borda o direito daquilo que é exibido, é o avesso que procuram resguardar com garan- 
tia de não invasão." Por que, no entanto, esconder o avesso? Como somos - estamos no trabalho? Olhemos, pois, o avesso. Assim, desejo que a experiência aqui narrada tenha promovido o resgate de memórias, a vontade de bordar histórias e perceber a beleza que há no avesso do bordado.

\section{REFERÊNCIAS}

BARBOSA, M. Experiência e Narrativa. Salvador: Ed. UFBA, 2003.

BRUNER, J. A Cultura da Educação. Porto Alegre: Artmed, 2001.

BURKE, K. A Grammar of motives. Berkeley: University of California Press, 1969.

CONNELLY, M.; CLANDININ, J. Relatos de Experiencia e Investigación Narrativa. In: LARROSA, Jorge et al. Déjame que te Cuente - Ensayos sobre Narrativas y Educación. Barcelona: Ed. Laertes, 1995.

CLANDININ, J.; CONNELLY, M. Pesquisa Narrativa: experiência e história de pesquisa qualitativa. Tradução: Grupo de Pesquisa Narrativa e Educação de Professores ILEEL/UFU. Uberlândia: Ed. UFU, 2011.

DORNELES, A. A bordadura da sala de aula de Química em Rodas de Formação. Curitiba: Appris, 2013.

LACERDA, N. Manual de Tapeçaria. 3. ed. Rio de Janeiro: Revan, 2006.

LARROSA, J. Notas sobre a experiência e o saber da experiência. Revista Brasileira de Educação, n. 19, p. 20-28, jan./abr. 2002.

LARROSA, J. Experiência e Alteridade em Educação. Revista Reflexão e Ação, Santa Cruz do Sul, v. 19, n. 2, p. 4-27, jul./dez. 2011.

LIMA, M. E. Sentidos do Trabalho: a educação continuada de professores. Belo Horizonte: Autêntica, 2005.

MARQUES, M. O. Escrever é preciso: o princípio da pesquisa. Ijuí: Ed. Unijuí, 1997.

MELLO, Dilma. Histórias de subversão do currículo, conflitos e resistências:

buscando espaço para a formação do professor na aula de língua inglesa do curso de Letras. 2005. Tese (Doutorado em Linguistica)-Pontifícia Universidade Católica de São Paulo, São Paulo, 2005. 
PASSOS, J.L. Ruínas de Linhas Puras: quatro ensaios em torno de Macunaíma. São Paulo: Annablume, 1998.

SOUZA, M. Histórias de Professores de Química em Rodas de Formação em Rede: colcha de retalhos tecida em partilhas (d)e narrativas. Ijuí: Ed. Unijuí, 2011.

SOARES, E. A arte de escrever histórias. Barueri: Manole, 2010.

SUÁREZ, D. A documentação narrativa de experiências pedagógicas como estratégia de pesquisa - ação - formação de docentes. In: PASSEGGI, M. C.; BARBOSA, T. (Org.). Narrativas de formação e saberes biográficos. São Paulo: Ed. Paulus, 2008.

SUÁREZ, D. Documentación Narrativa de Experiencias Pedagógicas: indagación-formación-acción entre docentes. In: PASSEGG, M. C.; SILVA, V. (Org.). Invenções de Vidas, Compreensão de Itinerários e Alternativas de Formação. São Paulo: Cultura Acadêmica, 2010.

SUÁREZ, D. Indagación pedagógica del mundo escolar y formación docente. Revista del IICE, n. 30. Buenos Aires: Instituto de Ciencias de la Educación, Facultad de Filosofía y Letras, Universidad de Buenos Aires, p. 17-32, 2011.

WERTSCH, J.; DEL RÍO, P. ALVAREZ, P. Estudos socioculturais: história, ação e mediação. In: WERTSCH, J.; DEL RÍO, P.; ALVAREZ, P. (Org.). Estudos Socioculturais da mente. Porto Alegre: Artmed, 1998.

Artigo Recebido em: 27 de setembro de 2015 Aceito em: 31 de janeiro de 2016

Endereço para correspondência: km 8, Avenida Itália, Carreiros, 96203-900, Rio Grande, Rio Grande do Sul, Brasil; lidorneles26@gmail.com 